\title{
AURAL SYPHILIS
}

kept, but no fresh skin lesions had developed during penicillin treatment or after it was stopped, and the established lesions appeared to have developed normally.

Air-cdre. McElligott said that he had seen more keratodermia in war-time than formerly. As often as not it was associated with non-specific urethritis, arthritis and metastatic conjunctivitis - the so-called Reiter's disease. The effect of the sulphonamides had been disappointing and hyperthermy had seemed to give the best results. He had not yet had an opportunity of trying penicillin in this condition.

Dr. C. Hamilton Wilkie said that he had seen quite a number of cases of hyperkeratosis, but he could recall one case, which might be of interest, of a young man whom he had seen some 10 years ago, and who then had urethritis, conjunctivitis and hyperkeratosis. Smears showed only a large Gram positive tetracoccus. That would not have been of any special interest but for the fact that he had retured 3 years ago with an exactly similar condition. The man had never had gonorrhoea. Dr. Wilkie had made many exhaustive tests and never found any evidence of a gonococcus. It might be of interest that on two occasions there was this large tetracoccus manifestation. He did not suggest that it was the cause, but it was present in association with the other conditions.

Dr. Harkness (in reply) agreed with Col. King that a parakeratotic balanitis was seen frequently in individuals suffering from acute polyarthritis, but he had not included such conditions in the present series of cases, even though they often preceded similar or nodular lesions in other parts of the body.

Brig. MacKenna had said that he considered that the superficial vesicles (harbouring gonococci) on the glans might be infected herpetic lesions. Dr. Harkness stated that on more than one occasion he had examined unruptured vesicles and that the aspirated contents had shown the presence of gonococci. Whether or not the inclusion bodies seen in the lesions of keratodermia blennorrhagica were the infective agent was a question which must be considered in the light of recent work. It had been proved by microdissection that the elementary bodies in molluscum and in fowl-pox (roup) were the infective agent, and this might be the case also in keratodermia blennorrhagica. Herzog and Fodor had regarded elementary bodies as changed forms of gonococci, but there was no evidence to support that contention.

Dr. Harkness was much interested in Col. Harrison's case of keratodermia blennorrhagica without urethritis and had mentioned in his address a similar case described by Lojander. He was particularly interested to hear from Col. Lees that the inoculum, in the successful inoculation experiments of Lees and Percival, had been the urethral discharge and not the cultured organisms.

\section{REFERENCES}

Fergusson, A. G., and Lees, F. J. (1943) Brit. J. Derm., 55, 125.

Lees, D., and Percival, G. H. (1931) Lancet, 2, 1116.

\section{AURAL SYPHILIS}

\author{
By T. RITCHIE RODGER, O.B.E., M.D., F.R.C.S.Ed. \\ Honorary Surgeon, Ear, Nose and Throat Department, Hull Royal Infirmary, and \\ Victoria Hospital for Children, Hull
}

This paper, contributed at the request of the Honorary Editor, is based on an address delivered in 1939 before the Section of Otology, Royal Society of Medicine. Matter in quotation marks is taken from the printed report of that address (Rodger ${ }^{2}$ ).

The burden of my theme on that occasion was the importance to the aural surgeon of being constantly on the alert for the presence of syphilis either causing or modifying the symptoms on account of which his advice is sought. It was suggested that there are two main reasons for such alertness. First, if an underlying syphilitic condition is present, the usual treatment for the symptoms complained of is likely to fail without the concurrent administration of antisyphilitic remedies. Even if the symptoms are due not exclusively to syphilis but to a more ordinary, perhaps a septic, condition occurring in a patient already the victim of syphilis, the "syphilitic terrain" will render the results of treatment uncertain. Secondly, and of even greater importance, if the symptoms which bring the patient to the aurist are syphilitic or are influenced by the presence of syphilis, then these symptoms constitute, just like the secondary rash or primary sore, a danger signal emitted by nature calling out for the recognition and treatment of the con- 
stitutional disease. If the aurist fails to recognize the signal in the domain for which he accepts responsibility, as the patient and his family doctor have probably failed to recognize other earlier signs, then one more opportunity of detection is lost and the syphilis remains untreated, with the risk to the patient of still more serious developments in later life, such as general paralysis or tabes.

What applies to the otologist is equally true of those practising in other departments of Medicine. Each practitioner should know, and should be on the look-out for, all the signs suggestive of syphilis in his own department. It may be admitted that the opportunities of such detection, and therefore the responsibilities, are greater in some specialties than in others. Probably the ear, nose and throat surgeon, the ophthalmologist and the neurologist have most need to keep syphilis constantly in mind. Circumstances of practice vary also in this respect. A general practitioner in a rural district may be excused for not being so alert in this matter as his fellow in a large city. I was in country practice in the early part of my career and, although I was responsible with my assistants for about 6,000 people, I did not see, or at any rate did not diagnose, more than 5 cases of syphilis in 10 years. My later interest in the subject was first aroused by this same element of disparity in practice. When I had been some 5 years established in special practice in a large seaport, I visited one day the out-patient clinic of a fellow aurist in another city. After a patient had left the room, I asked my friend whether there was not a possibility of syphilis in that case. He replied that it had not occurred to him, as he saw syphilis so seldom. He questioned whether he saw a dozen cases in a year. It occurred to me then that, working in such a city as mine, I might have a better opportunity than most of my colleagues of doing some statistical research on the subject, and straightway I began to keep a detailed record of such cases. In the next 10 years I had collected notes of 500 cases and it is on these cases that my present observations are based.

\section{Diagnosis of syphilis}

If we agree that it is incumbent on every practitioner to make himself fully conversant with the signs of syphilis in his own specialty or department, what on the other hand is the rest of the profession entitled to expect of the syphilologist? Probably most of the cases which come to him directly for diagnosis are patients with primary sores, men and women conscious of having incurred the risk of infection and induced to come to him by the well-known placards urging early and free treatment. Most of the secondary and tertiary cases presumably come to him for treatment with a diagnosis already achieved by another practitioner or consultant, with the conclusive aid of a positive blood test. If this is so, it seems to me that the syphilologist should exert himself to claim a better share in the diagnostic team work. He should be more than a purveyor of treatment, much more than merely the man in his area who is most up to date and most reliable in the administration of antisyphilitic drugs and who knows best when to use one drug and when another. He should be all these things, and in addition he should be the man who knows more than does any other about all the possible manifestations of syphilis in all the regions of the body, and to whom all other practitioners can turn with confidence for help in a doubtful case. For instance, I may have a case in my own department which from my experience is suggestive to me of syphilis, but the blood examination of which yields a negative result. I may seek the help of a general physician who may be expected to be able to detect some other signs not obvious to me. He on his part however may feel that the ophthalmologist and the neurologist might be able to find something in their departments not obvious to him, and thus the patient goes the round.

Is the science of syphilology too extensive for us to expect that the practitioners of that department should become so much au fait with the vagaries of syphilitic manifestations in all regions and systems of the body that we, in other departments of Medicine, can come to look on them as our natural refuge in doubtful and difficult cases? 
I can appreciate that in private practice there may be a difficulty in some cases, in so far as it may be awkward to call in consultation one who is known locally to be confined to that particular specialty ; but in hospital work, which represents by far the largest and a growing proportion of our cases, the difficulty need not arise if the syphilologist is made a member of the staff. In my city, when the venereal diseases clinic was first established, the local authority rented accommodation for it from the Royal Infirmary. In my own department there we found it to be-very convenient to refer patients for treatment when-as in the numerous cases of women infected by erring husbands and quite unsuspicious of the nature of their condition-we might wish not to declare the diagnosis immediately.

After a few years the local authority built a new venereal diseases clinic in another street, and we then found ourselves at a disadvantage, as a reference to the new address was equivalent to declaring a diagnosis. Other members of the staff, especially the ophthalmic surgeons, were impressed by the same disadvantage, and we made representations to the Infirmary Board through the staff committee, asking them to appoint the venereal diseases specialist an honorary member of the staff with a regular out-patient day like the rest of us. This plan has worked well for 20 years and I expect that it is functioning in a large number of similar hospitals. Thus for probably nine-tenths of our cases there need be no difficulty about the syphilologist being the consultant of choice in a suspected case.

\section{Incidence of syphilis}

It may be assumed that we shall see a marked rise in the incidence of syphilis as a result of World War II, as happened during and after World War I. My friend Dr. Barlee has kindly furnished me with statistics from the Hull Venereal Diseases Clinic. In 1920 and 1921 the cases numbered 684 and 557 respectively. In 1934 they had fallen to 246 and in 1938 to 150 . It is noteworthy, however, that during the years of my own investigation, 1924-1934, the new cases coming under my care remained fairly constant round about 50 each year, the reason being that nearly all my cases were of tertiary or late secondary conditions with a varying time incidence in relation to the primary infection.

The late deafness of hereditary syphilis constitutes the largest single group of aural syphilis and, as is mentioned below, this comes on as a rule between the ages of 8 and 15 years. In the years between 1934 and 1939 I had not the same opportunity of collecting detailed figures, as the work at my two hospitals was by that time shared by a colleague; but as far as I have been able to form an estimate, the number of cases had fallen to less than one-half by 1938, as would be expected from the combined effect of the improved efficiency of treatment and the distance in time from the maximum incidence of the disease after the war of 1914-1918. The fall was particularly noticeable in the hereditary cases. In the last few years $I$ have seen the deafness of hereditary syphilis comparatively rarely-even more rarely than is accounted for by Dr. Barlee's figures-and I take this to be due mainly to efficient treatment of the parent. It is what we should expect. I remember, in 1928, asking the superintendent of our mental hospital whether his admissions for general paralysis of the insane had shown a drop since the institution of the arsenical treatment. His reply was in the negative, but he reminded me that the average onset of general paralysis was 20-25 years after infection, and that we had not been using the new treatment extensively for that length of time. His successor, however, was able to inform me 10 years later that there was now a very marked fall in such admissions. In the case of congenital-syphilis we have not had to wait so long for evidence of the efficiency of modern treatment.

\section{Types of aural syphilis}

Let us now attempt to classify and describe the chief types of aural syphilis found in the 500 cases referred to. It must be understood that this total included 
many cases of syphilis of the nose and throat without involvement of the ear, but it is only with aural manifestations that I wish to deal in this paper.

\section{Deafness in hereditary syphilis}

In congenital syphilis the foetus has been infected from the blood stream of the mother during pregnancy. The infection is general from the outset and is comparable with the secondary stage of the acquired disease. The primary stage is absent.

"We have thus in hereditary syphilis to consider only the secondary and tertiary stages of the disease and the two main classes of ear manifestations correspond with these two stages. French otologists speak of the "précoce" and the "tardive" [syphilis] types, just as we speak of the early and late. The . . . . early type includes not only the meningoneuritis and meningo-neurolabyrinthitis associated with syphilitic basal meningitis, but also otolabyrinthitis, the effects of which are confined mainly to the labyrinth and the middle ear. These two early types admittedly belong to the secondary stage of syphilis. The . . . late type is exemplified chiefly by deafness following interstitial keratitis generally about the age of 9 years, and this is mainly a labyrinthitis. Hutchinson was at one time inclined to include these cases also as belonging to the secondary stage of the disease, on account of the eye and ear conditions being as a rule bilateral. It is to be noted, however, that the affections of the eye and ear are only ultimately bilateral. The lesion begins on the one side, and weeks or months later the other is affected. There is thus a marked contrast to the skin conditions of the secondary stage of the acquired disease, in which the rash appears with more or less constant symmetry.", (Rodger ${ }^{2}$.)

One important difference between the early and the late cases of hereditary syphilitic deafness consists in their effect on speech. In the early cases the loss of hearing most frequently occurs before the child has learned to speak, and he is destined to be a deaf-mute, whereas in the late cases speech has as a rule been established and, although the loss of hearing may be extreme, speech is likely to be maintained, probably however in the monotonous voice peculiar to the very deaf.

In both types of case the child will have to depend upon lip-reading for his appreciation of the spoken word, but the process of acquiring this accomplishment is very different in the two types.

Early onset.-When hearing has been lost very early, before speech has been established, education in a school for the deaf will be necessary. Nothing can be more praiseworthy than the painstaking devotion of the teachers who undertake this work. By careful use of the lips and tongue, by allowing the pupils, when it is necessary, to feel the motions of the teacher's lips and larynx and by patient correction of faulty enunciation, they get the brighter children, at least, to acquire sufficient expression to make themselves understandable. If there is some small residue of appreciation of sound, a recording audiometer helps greatly in developing tone in the voice. As a rule, if a child does not speak with a toneless monotonous voice it is because there is some remnant of hearing left, even if it is not enough to enable him to hear a shout.

Later onset.--In the older children, however, when deafness supervenes after speech has been acquired and education begun, it is very different. The child picks up lip-reading of his own accord, without tuition, and he can continue his education at an ordinary school. Indeed he may be almost entirely dependent upon lip-reading without the teacher or the mother having noted the fact. My colleague, R. R. Simpson, and I made this interesting observation some 10 years ago, when we were asked to examine a group of partially deaf children. The Senior School Medical Officer had in mind the advisability of providing special classes for children who were too deaf to get the full benefit of teaching in ordinary classes, but who were not deaf enough to be certifiable for admission to the School for the Deaf. He asked the teachers to send to us any such cases for a detailed examination. These children were not syphilitic cases; they were mainly post-suppurative cases and cases of catarrhal otitis media, but among them there were about 20 who were so deaf that the whispered voice could not be heard by them at a greater distance than 6 inches with either ear tested separately ; yet each one of these children, when allowed to see the examiner's face in a good 
light, responded correctly at 20 feet. Some of the mothers expressed astonishment ; they had not realized the fact that, in their ordinary communication with their children, the latter were depending so much upon lip-reading.

The cases of late hereditary syphilitic deafness, which occur most commonly when speech has been established for years, have the advantage of this easy acquisition of lip-reading. It is only the very unintelligent who experience difficulty. This is in direct contrast to the case of the person who becomes deaf in later life, as for example from otosclerosis or certain forms of nerve deafness. Even with expert tuition an adult, however. intelligent, seldom becomes as proficient as does a child in lip-reading.

\title{
Hereditary syphilis and deaf-mutism
}

\begin{abstract}
" It may be convenient at this point to refer further to the relationship between hereditary syphilis and deaf-mutism. The Wassermann test as applied to any series of deaf-mutes is not a completely reliable guide. Everyone knows that it is common enough to obtain a negative Wassermann, and even a second negative after provocative medication in congenital syphilis, when Hutchinson's teeth and interstitial keratitis leave no reasonable doubt as to the condition. Urbantschitch (as quoted by Ramadier) records 14 per cent of positive results in a series of deaf-mutes. In the deaf school in Hull, where we have made a point of securing a blood examination for every entrant if the parents agree, the proportion of positive reactions to the Wassermann test was 19 per cent. We may safely conclude that the actual proportion of syphilitic children in the school is at least 25 per cent, the figure arrived at by G. de Parell and separately by Beck, (as quoted by Ramadier), basing their conclusions on an investigation of the family history as well as the serological tests." (Rodger ${ }^{2}$.)
\end{abstract}

\section{Pathology of early cases of hereditary syphilis}

Auditory nerve and internal ear.-Meningoneuritis affects the auditory nerve as part of a syphilitic meningitis. Post-mortem appearances of an infection which had arisen in the subarachnoid space and infiltrated the fibres of the auditory nerve, then the perivascular spaces of the columella (modiolus of cochlea), the spiral ganglion and the organ of Corti, have been described by Mayer. Similar findings have been recorded by Haik (Ramadier).

Internal and middle ear.-Otolabyrinthitis, in which the attack is on the middle ear, is of more frequent occurrence. Sudden onset without pain or malaise is a characteristic feature. A little pus on the pillow may be the first indication. Such a painless onset may indeed occur also in tuberculous otitis media and even sometimes in the more common types of suppuration, but it is so characteristic of the otolabyrinthitis of syphilis that it is a good rule always to think of the latter when pain is absent. Fournier thought that a large proportion of all the cases of bilateral otitis media in very young children were due to syphilis. Brockaert and Cheatle (Ramadier) opposed this view, and I agree with them. A few years ago I made an analysis of my cases of otorrhoea in children under 3 years of age, and was surprised to find that in 40 per cent of them the condition was bilateral ; this was not necessarily the case when they were first seen, but the second ear had required treatment within a week or two of the other. In very few of these cases did the infection prove to be syphilitic.

In cases of syphilitic otolabyrinthitis the spirochaetes, with their predilection for periosteum and perichondrium, probably attack first the mucoperiostium of the inner wall of the middle ear. This is followed by infiltration of the thin plate of bone, giving rise to definite changes on both aspects of it. In the middle ear there is suppuration, in the internal ear invasion of the cochlea with destruction of the delicate nerve endings. The process may vary with preponderance of effect to one side or the other of the party wall. Sometimes there is no obvious middle ear discharge, the damage being confined to the labyrinth. Baratoux, in a series of necropsies, found the lesion limited to the labyrinth in 4 cases, whereas 12 showed lesions involving both labyrinth and middle ear (Ramadier).

Delay in diagnosis.-It is somewhat distressing, in connexion with these cases of the early type, whether due to meningitis or to otolabyrinthitis, that the diagnosis is usually made in retrospect and after the internal ear has been 
damaged beyond repair. The child is brought for examination because he makes no attempt to speak and is thought to be unable to hear even loud noises. Careful enquiry elicits a story of previous illness at the age of (most commonly) 1 year or 18 months-an illness probably not diagnosed as meningitis, but in which the child was unconscious for a few days-or there may be a history of a painless otorrhea, such as is described above. In my series I classed 4 cases as being due to meningitis and 11 to otolabyrinthitis.

\section{Deafness of late onset in hereditary syphilis}

When a child who is the subject of congenital syphilis has passed through his first few years of life without falling a victim to either of the early forms of ear disease described above, he has still to run his greatest risk as far as loss of hearing is concerned. This is the specific labyrinthitis which, with notched teeth and interstitial keratitis, forms the well-known Hutchinsonian triad. It constitutes the largest and most distinctive group of ear affections arising from congenital syphilis. In my series it occurred in 44 out of a total of 121 cases of hereditary syphilis and was 3 times as common as were both the early types together. The age of onset is generally between 8 and 15 years, but it may occur as early as 4 years and in 2 of my cases it first appeared at 45 and 47 years respectively. The deafness, like the interstitial keratitis, is always ultimately bilateral. The ear condition nearly always supervenes 2 or 3 years after the keratitis. In only one of my cases did it antedate the eye condition. The late J. S. Fraser has also reported one such case (Mayer and Fraser).

This form of deafness does not occur in the acquired disease. Ramadier found in the literature of the subject 3 cases attributed to acquired syphilis but, in view of the histories, doubted the accuracy of the allocation. The cases referred to above, in which the deafness began at 45 and at 47 years, had to be very carefully investigated in this connexion, but the signs of past keratitis and the age at which the keratitis occurred, as well as other stigmata, seemed to me to leave no doubt.

Hutchinson found that females are affected twice as frequently as are males, and in my series it was exactly so ; other observers have confirmed this. Tinnitus is very common. The noises may precede the deafness and may persist long after all useful hearing is lost. Vertigo is as common as is tinnitus and occurs in all degrees of severity. One of my patients had fallen downstairs and another could not go out alone. Spontaneous nystagmus however was noted only in two cases.

Pathology.-Mayer and Fraser have described miliary gummata in the endosteum of the labyrinth and it is generally accepted that the pathological condition is confined to the labyrinth, without any involvement of the middle ear or meninges. Ramadier in 39 cases (78 ears) found that 19 per cent of the patients could not hear a shout ; in my 44 cases ( 88 ears) 29 per cent failed in the same test. Hutchinson, who first described the condition in 1863, was at first misled on the question of middle ear involvement. He had based his description on 21 cases and says that in the first 15 he had too readily accepted statements of past ear discharge, this being in accord with his expectations. He admits that no detailed examination of the ears was attempted. In the last 6 cases however, feeling himself to be on the track of something new, he had enlisted the help of a colleagıe ; all these cases showed no evidence of past or present middle ear disease. He therefore concluded that "the deafness in these cases is either due to disease of the nerves or of their distribution in the labyrinth "'.

Diagnosis.-As a rule diagnosis does not present much difficulty. As mentioned above, the otoscopic appearances are likely to be normal. The eustachian tubes are also, as a rule, patent. The functional tests however are very distinctive. The deafness is of more extreme degree than is usual for a catarrhal or suppurative otitis media. It is never associated with coincident affections of other cranial nerves. The degree of deafness depends largely upon how early the case comes under observation. As Ramadier puts it, "the loss of hearing is always severe or destined to become so'. 
Bone conduction is not increased relatively to air conduction, as it is in otitis media ; indeed it is as a rule largely lost except for the low frequencies. The presence of tinnitus also serves to distinguish the condition from otitis media, in which noises are not often complained of by young patients. It is almost invariably the rule that the vestibular apparatus as well as the cochlea is affected. Although the subjective complaint of giddiness is often absent, either because the child has forgotten it or has paid little attention to it, the objective tests nearly always indicate a partial or complete abrogation of vestibular function. If the cold caloric test (for Bárányi's symptom) or rotation tests give a normal or nearly normal reaction, whereas the severe deafness with loss of bone conduction combined with keratitis indicates the nature of the condition, a further test after a period of observation is almost certain to reveal loss of vestibular reaction.

Coincident syphilitic lesions of the nose, pharynx or palate, or scars and gaps indicating such healed lesions, are quite common but are not constant like the interstitial keratitis. In my 44 cases, 15 showed such lesions and 40 had unmistakable signs of the eye affection.

\section{Ear conditions in acquired syphilis \\ In primary syphilis}

The primary sore is said to occur occasionally on the auricle as a result of biting or kissing or of piercing the lobe with an infected instrument, but I have not myself met with it. It is said also to have occurred at the lower orifice of the eustachian tube from the use of an unclean catheter.

\section{In secondary syphilis}

In the secondary stage syphilides may be found on the auricle as on any other part of the skin. Condylomata may occur in the external auditory meatus on account of the relatively moist conditions there. My series included 3 such cases, which cleared up quickly under antisyphilitic treatment. The middle ear affections of the secondary stage correspond to a large extent with those described above as occurring in early congenital syphilis. There may be a catarrhal or suppurative otitis media dependent upon a specific lesion in the pharynx or nasopharynx. Seven such cases occurred in my series and all resolved quickly without loss of hearing when the throat lesions responded to treatment. On the other hand there may be a genuinely syphilitic condition in the middle ear, analogous to the otolabyrinthitis described above. The onset is sudden and the degree of deafness out of all proportion to the otoscopic signs. Tinnitus and giddiness are generally severe and bone conduction much diminished. As in the congenital cases, there may or may not be otorrhoea. The inner aspect of the party wall may be mainly involved with little to show in the middle ear.

Internal ear and auditory nerve.-The most common ear conditions of the second stage, however, in the acquired disease as in the congenital, are those affecting the perception apparatus without any involvement of the middle ear at all. This meningo-neurolabyrinthitis, similar to that described above, is by far the most common condition found in the secondary stage. A very severe deafness of sudden onset, with, as a rule, noises and giddiness, and occurring in a comparatively young person, should at once raise the question of syphilis. Ménière's symptom-complex belongs for the most part to later age groups.

As this nerve deafness of the secondary stage is apt to coincide in time with the period of active treatment, a controversy arose on the continent of Europe as to whether or not it was due to arsenical poisoning. Ramadier discusses the question at considerable length and comes to the conclusion that it is a true syphilitic deafness, but that it may not be unconnected with the arsenical treatment. In his view, underdosage may be the cause of failure to prevent the onset of the syphilitic deafness. The full efflorescence of the secondary signs indicates and coincides with the maximum output of the antibodies which nature prepares as its own contribution to the fight against the spirochaetes. It is possible, he says, that insufficient medication, by suppressing this reaction, may really 
deprive the tissues of a greater amount of natural protection than is being artificially supplied. The loss is apt to affect especially the less vascular nerve tissues, and thus the auditory nerve is attacked. He therefore concludes that if deafness supervenes during treatment the drug should be pushed rather than stopped.

\section{In tertiary syphilis}

In the tertiary stage gummata may occur on the auricle or in the meatus. In 2 of my cases ulceration in the meatus, with granulations, had to be distinguished from the condylomata already referred to as occurring in 3 cases. One patient however had an obviously tertiary condition on the forehead and the other showed 2 large healed gaps in the nasal septum. In both patients the ear condition resolved after 2 weeks of antisyphilitic treatment; in the former the forehead lesion had also healed, although it had previously resisted various local applications over a period of 18 months.

In the middle ear an incidental catarrhal or suppurative condition may occur, arising from syphilitic ulceration in the pharynx, palate or nasopharynx; alternatively a genuine syphilitic otolabyrinthitis may be found which produces both middle ear and internal ear signs. In my series I classed as otolabyrinthitis 7 cases, of which 4 were bilateral. In the mastoid process a sequestrum with or without suppuration may occur, as in one of my cases in which the posterior bony wall of the meatus was mobile. In another case the periosteum was thickened and densely adherent.

Internal ear and auditory nerve.-By far the most common ear condition found, however, in the tertiary stage as in the secondary, is neurolabyrinthitis. It has been suggested that it may be due to miliary gummata in the endosteum of the labyrinth, similar to the condition described by Mayer and Fraser in the late hereditary cases, but post-mortem confirmation of this theory is awaited.

The neurolabyrinthitis of acquired syphilis is most often bilateral. Of 52 cases in my series, 39 were bilateral. The other 13 remained unilateral all the time they were under observation, so that the condition is probably not uniformly bilateral as in the late congenital cases. Tinnitus and giddiness were troublesome in about one-half of the cases. Spontaneous nystagmus was noted 3 times. The cold caloric test yielded a normal reaction more frequently than not, in marked contrast to the results of this test in the late congenital group. Coincidental paralyses, which never occur in the congenital type, were noted 7 times: 3 facial and 3 vocal cord paralyses and one ptosis. In 8 cases tabes dorsalis was present before deafness occurred. In one other tabetic patient, severe deafness had suddenly supervened and seemed to be of the neurolabyrinthitis type, but 5 weeks later aural discharge was present and I had to class her case as otolabyrinthitis. Treatment produced a dry ear but no restoration of hearing.

\section{Conclusions}

It will be gathered from what is said above that, in the most common forms of aural syphilis, the outlook as regards function is not good. The less often-met cases of coincidental catarrh or suppuration, occurring in the syphilitic terrain or dependent upon syphilitic lesions in the vicinity of the eustachian tube, ought to resolve completely if suitable local treatment is combined with adequate antisyphilitic medication. Cases of otolabyrinthitis in which the effects of the condition are confined mainly to the outer aspect of the party wall should also respond well to antisyphilitic treatment, especially if the diagnosis is arrived at in good time.

In the more common cases, however, in which the labyrinth is chiefly involved, the delicate nerve endings of the cochlear nerve, enclosed in the very restricted bony space, readily succumb to the effects of pressure from the inflammatory exudate, and treatment is not likely to restore the function.

Our hope lies in prevention of the onset of these ear conditions, and there is accumulating evidence that in the last generation we have begun to achieve this. 
The activities of the venereal diseases clinics and the general upgrading of treatment have caused a marked fall in the incidence of ear conditions of syphilitic origin, both in the acquired and congenital forms of the disease. Because of the improved treatment of the prospective parent there should be fewer and fewer infected children born. If we keep in mind that by far the most common ear condition in congenital syphilis occurs after the age of 8 or 10 years, and if we insist accordingly on continued treatment and after-care up to and beyond that age, we ought to be able to prevent a large proportion of the deafness which otherwise might occur.

There is one other point to which I should like to refer again. In the course of going into the history of deaf-mutes $i \cdot r$ certification as to their eligibility for the School for the Deaf, I have been struck by the large number of cases in which a history of severe but ill-defined illness at the age of 1 year or 18 months is elicited. Often it is reported that the doctor had said that he "was afraid of . meningitis", or something else may have been diagnosed; but the mother remembers that the patient was unconscious for some days. If it were generally kept in mind that a syphilitic basal meningitis is apt to behave just like thiswithout a frank exhibition of all the cardinal signs of the acute condition-then the practitioner would resort to a blood examination and have the proper treatment instituted in time to avert the disaster to the nerve of hearing.

I wish to acknowledge my indebtedness to the Honorary Editors of the Proceedings of the Royal Society of Medicine for permisssion to quote from their published report of the meeting of the Section of Otology.

\title{
REFERENCES
}

Fournier, J. A. (1886) La syphilis héréditaire tardive, Paris.

Hutchinson, J. (1863) Clinical Memoir on certain Diseases of the Eye and Ear consequent on inherited Syphilis, London.

Mayer, O., and Fraser, J. S. (1936) J. Laryng., 51, 683, 755.

Ramadier, A. F. F-J. (1928) La syphilis auriculaire; oreille et nerf acoustique, Paris. Rodger, T. R. (1937)i, Proc. R. Soc. Med., 30, 1294.

- (1939) $)^{2}$ ibid, 33, 87.

\section{TREATMENT OF VENEREAL DISEASES IN THE ALLIED MERCHANT NAVIES}

\author{
By A. O. F. ROSS, M.D., D.P.H. \\ Director, Venereal Diseases Clinics, City and Port of Liverpool; Lecturer in Specific Diseases, \\ University of Liverpool
}

The centre in which the treatment described below was given is the Liverpool Corporation Seamen's Dispensary, a small building erected in 1923 for the purpose which it serves.

It is within a hundred yards of the three main Seamen's Homes and the Merchant Navy Reserve Pool Offices. It is an ad hoc venereal diseases centre for outpatients, with a small laboratory in which microscopical slide preparations for the diagnosis of gonorrhoea and syphilis can be examined immediately. Serological tests are performed thrice weekly at the City Laboratories, and thus rapid diagnosis is made possible. The great majority of the patients are seafarers, and a close liaison between this centre and the medical superintendents of the shipping companies, the medical officers of the Shipping Federation and the various consulates of maritime nations, has always existed within the limits of professional confidence and of the Venereal Diseases Regulations of 1916. Certificates stating probable duration of absence from sea service, and of fitness to serve at sea for a stated period of 3 or 6 months, are given to the patient in person, and he is at liberty to utilize or destroy the certificate as he wishes. Of recent years, the Allied Merchant Navies of Belgium, France, Holland, Norway and Poland have set up 